\title{
Molecular structure and charge density analysis of $p$-methoxybenzoic acid (anisic acid)
}

\author{
R. Fausto ${ }^{\mathrm{a}, *}$, A. Matos-Beja ${ }^{\mathrm{b}}$, J.A. Paixão ${ }^{\mathrm{b}}$ \\ ${ }^{a}$ Departamento de Química, Universidade de Coimbra, P-3049 Coimbra, Portugal \\ ${ }^{\mathrm{b}}$ Departamento de Física, Universidade de Coimbra, P-3000 Coimbra, Portugal
}

Received 15 January 1997; accepted 2 April 1997

\begin{abstract}
A concerted X-ray and ab initio SCF-MO study of the structure and charge density of $p$-methoxybenzoic acid (anisic acid) is reported. An extensive X-ray data set (7401 reflections) was measured on a single crystal using Mo K $\alpha$ radiation and the structure refined with 2121 unique reflections, leading to a final $R(F)$-factor of 0.047 calculated for reflections with $I>2 \sigma$. The molecular geometry of crystalline anisic acid, where the molecules dimerize via a moderately strong $\mathrm{C}=\mathrm{O}-\mathrm{H} \cdots \mathrm{O}$ hydrogen bond, is compared with that of the isolated molecule, resulting from SCF-MO ab initio calculations. A topological analysis of the molecular charge density was performed using Bader's method to gain insight into the dominant intra- and intermolecular interactions in this compound. In particular, the effects of the substituents on the observed distortions of the benzene ring were investigated as well as the internal rotation of the methyl group. (C) 1997 Elsevier Science B.V.
\end{abstract}

Keywords: Ab initio calculations; Hydrogen bonding; $p$-Methoxybenzoic acid; X-ray crystallography

\section{Introduction}

The crystal structures of alkoxy-substituted benzoic acids have been the subject of several X-ray crystallographic studies [1-6], as these compounds show interesting chemical properties. In particular, certain members show liquid crystalline behaviour on melting $[7,8]$. From the structural point of view, it is interesting to investigate both the influence of the substituents on the geometry of the benzene ring andhow intramolecular interactions (in particular H-bonding) affect the geometry of these molecules. These days such questions can be addressed by X-ray

\footnotetext{
* Corresponding author.
}

investigations as well as by ab initio quantum chemical calculations.

In the case of anisic acid, the most recent crystallographic study was performed in 1978 by Colapietro and Domenicano [6]. The structure was refined by full matrix least-squares using 931 Bragg reflections with $I>4 \sigma$ measured on an X-ray diffractometer, leading to a final $R$-factor of 0.037 . The structure analysis was much more precise than the original data of Bryan [9], who first determined the crystal structure of anisic acid using intensities recorded on photographic film. In particular, Colapietro and Domenicano were able to observe small distortions in the benzene rings of the dimeric units present in the crystal, deviating from its ideal geometry due to the effect of the substituents. However, to our knowledge, no structural data 
obtained either by experimental or theoretical methods have been reported so far for the monomer of anisic acid. Thus, in order to characterize in detail both the intra and intermolecular interactions present in the studied compound, it appeared to be essential to undertake a detailed comparative study of the isolated molecule and the solid state unit. In the present study, a concerted approach by X-ray crystallography and ab initio MO calculations was used, which takes advantage of both the high interpretative power of the theoretical studies and the precision and reliability of the experimental method.

Because we noticed that the structural data of Colapietro and Domenicano were obtained using a relatively high threshold for the intensities included in the structure refinement (when all weak reflections, $I<4 \sigma$, were neglected in the analysis), we decided to perform a new single-crystal X-ray data collection for anisic acid, and to analyse our data including the weak reflections as well as the strong ones. Indeed, it is well known that the use of a threshold for ignoring weak reflections may introduce a bias on the structural parameters $[10,11]$, and it is nowadays generally accepted that it is preferable to use all measured data except for those reflections known to suffer from systematic error.

To analyse the molecular charge density, Baders's topological method [12-14] is used, as it constitutes an adequate method for the characterization of the various interactions present in a molecular system in terms of interactions between atoms or between molecular fragments. In addition, the $-\mathrm{CH}_{3}$ internal rotation is analysed and its effects on the molecular properties discussed.

\section{Experimental and computational methods}

\subsection{X-ray diffraction studies}

The X-ray data collection was performed using Mo $\mathrm{K} \alpha$ radiation on an Enraf-Nonius CAD4 diffractometer equipped with a graphite monochromator. A transparent polyhedric crystal with approximate dimensions of $0.20 \times 0.20 \times 0.25 \mathrm{~mm}^{3}$ was selected for this study from a batch of a commercial product (Merck, 99\% purity) and mounted on a fibre capillary in a random orientation. Cell constants and orientation matrix for data collection were obtained by a leastsquares procedure from the setting angles of 25 reflections in the angular range $17^{\circ} \leq 2 \theta \leq 37^{\circ}$ centred by the diagonal slit method. The monoclinic cell parameters are: $a=16.961(2) \AA, b=10.958(1) \AA, c=$ 3.9662(5) $\AA, \beta=98.12(1)^{\circ}$, in good agreement with previous work [6]. This compound crystallizes in the space group P2 $1 / a$ (spg. nb. 14), $Z=4, d_{c}=1.38 \mathrm{~g} \mathrm{~cm}^{-3}$.

Data were collected at room temperature (296(3) K) using $\omega-2 \theta$ scans covering the range $2.4^{\circ} \leq \theta \leq 30^{\circ}$. The scan width was determined as a function of $\theta$ to correct for the separation of the $\mathrm{K} \alpha$ doublet, $\Delta \omega=$ $1.5+0.344 \tan \theta$. The counter aperture was also adjusted as function of $\omega$. For intense reflections, an attenuator ( $\mathrm{Zr}$ foil) was automatically inserted in front of the detector. The $\omega$ scan-rate varied from 1 to $5^{\circ}$ $\min ^{-1}$ and the profiles of the reflections were collected with a background/peak time ratio of 0.5 .

A total of 7401 reflections was measured in the range $-23 \leq h \leq 23,-15 \leq h \leq 15,-5 \leq l \leq$ 5 , covering the whole Ewald-sphere accessible to the diffractometer within the above mentioned $\theta$ limits. As a check on the crystal and electronic stability, a set of 5 intensity-control reflections was measured every $120 \mathrm{~min}$. The crystal showed excellent stability in the beam: the slope of the least-squares line of intensity vs. time corresponds to an intensity loss of only $1.2 \%$ at the end of the data collection.

Lorentz and polarization corrections were applied to the data, but no absorption correction $\left(\mu=1.0 \mathrm{~cm}^{-1}\right.$ for Mo $\mathrm{K} \alpha$ radiation). The internal agreement factor of the symmetry-equivalent reflections was excellent, $R_{\text {int }}\left(F^{2}\right)=1.5 \%$.

Refinement of the crystal structure was performed by full-matrix least-squares refinement using the computer program SHELXL93 [15]. The calculations were performed on a Pentium $150 \mathrm{MHz}$ PC running the LINUX operating system. All measured reflections were included in the refinement, including the weak ones, except for a few reflections with very negative intensities due to a poor integration. The quantity minimized by the least-squares procedure was $\sum\left(F_{\mathrm{o}}^{2}-F_{\mathrm{c}}^{2}\right)$, where $F_{\mathrm{o}}^{2}$ and $F_{\mathrm{c}}^{2}$ are the observed and calculated intensities, respectively. The weight assigned to each reflection was $w=1\left(\sigma^{2}\left(F_{\mathrm{o}}^{2}\right)+\right.$ $\left.(0.0571 P)^{2}+0.11 P\right), P=\max \left(F_{\mathrm{o}}^{2},\left(F_{\mathrm{o}}^{2}+2 F_{\mathrm{c}}^{2}\right) / 3\right)$. This weighting scheme was chosen to produce a flat analysis of variance in terms of $F_{\mathrm{c}}$. 
Initial atomic positions of the non-H atoms were taken from the earlier work of Colapietro and Domenicano [6] and refined anisotropically. The positions of the hydrogen atoms were located on a difference Fourier synthesis and refined with isotropic temperature factors. Scattering factors and anomalous dispersion coefficients were taken from the International Tables for Crystallography [16]. The last cycle of refinement included 132 parameters and a total of 2121 unique reflections. After convergence (last cycle had a maximum shift/esd of 0.001), the final residual factors were $w R\left(F^{2}\right)=0.099, \chi^{2}=$ 1.04. It should be pointed out that as the refinement was based on intensities $\left(F^{2}\right)$ and not on the scattering amplitudes $(F)$, the value of the $R\left(F^{2}\right)$ factor is expected to be about twice the value of a conventional $R(F)$-factor. In fact, $R(F)=0.047$ for 1025 reflections with $I>2 \sigma$ and $R(F)=0.033$ calculated for 843 reflections, satisfying the condition $I>4 \sigma$. This last value should be compared with the value $R(F)=0.037$ obtained by Colapietro and Domenicano using the same threshold. Thus, although we have measured a larger data set including many equivalent reflections, the final agreement factors of our structure refinement are only marginally better than those of Colapietro and Domenicano. The highest and lowest peaks in the final difference Fourier map were 0.23 and $-0.19 \mathrm{e}^{-3}$, with an estimated mean error on the residual density of $0.06 \mathrm{e}^{-3}$.

\subsection{SCF-MO calculations}

The Hartree-Fock ab initio SCF-MO calculations were carried out on a DEC ALPHA 7000 computer using the Gaussian 92/DFT program system [17] and the $3-21 \mathrm{G}$ basis set [18]. This basis provides a good compromise between computer time and the quality of the results [19-21].

The optimized equilibrium molecular geometries with the $C_{\mathrm{s}}$ symmetry constraint were obtained by the gradient relaxation method of Pulay [22], using Berny's algorithm [23], which evaluates the gradient analytically. The maximum residual internal coordinate forces on the optimized coordinates are always less than $3 \times 10^{-4}$ hartree bohr $^{-1}(1$ hartree $=$ $\left.2625.5001 \mathrm{~kJ} \mathrm{~mol}^{-1} ; 1 \mathrm{bohr}=5.29177 \times 10^{-11} \mathrm{~m}\right)$ or hartree $\mathrm{rad}^{-1}$. Within these conditions, the absolute errors in bond lengths and bond angles with respect to the true equilibrium geometrical parameters are less than $0.01 \AA$ and $0.1^{\circ}$, respectively. The stopping criterion for the SCF iterative process required a density matrix convergence of less than $10^{-8}$.

The $C_{\mathrm{s}}$ symmetry constraint imposed on the benzene ring can be important in accessing the relative energies of planar and nearly planar conformations, but it was found to introduce only small changes in the geometrical parameters.

The analysis of the wave functions in terms of the charge distribution was carried out by Bader's topological method [12-14], using the PROAIM package [14].

\section{Results and discussion}

The atomic positions derived from the X-ray study describing the crystal structure of anisic acid and the equivalent isotropic displacement parameters of the anisotropic (for non-H atoms) or isotropic (H atoms) $U_{i j}$ tensor are given in Table 1 , together with their estimated standard deviations (esd).

Table 1

Atomic coordinates and equivalent isotropic displacement parameters $\left(\AA^{2} \times 10^{3}\right) . U_{\text {eq }}$ is defined as one third of the trace of the orthogonalized $U_{i j}$ tensor

\begin{tabular}{llrrl}
\hline & $x$ & \multicolumn{1}{l}{$y$} & $U_{\text {eq }}$ \\
\hline O1 & $0.0690(1)$ & $-0.0788(1)$ & $-0.1792(4)$ & $64(1)$ \\
O2 & $0.0754(1)$ & $0.1103(1)$ & $0.0250(4)$ & $64(1)$ \\
O3 & $0.4238(1)$ & $0.0477(1)$ & $-0.3415(4)$ & $57(1)$ \\
C1 & $0.1888(1)$ & $0.0309(1)$ & $-0.1791(4)$ & $41(1)$ \\
C2 & $0.2256(1)$ & $-0.0651(2)$ & $-0.3267(5)$ & $46(1)$ \\
C3 & $0.3037(1)$ & $-0.0567(2)$ & $-0.3767(5)$ & $49(1)$ \\
C4 & $0.3472(1)$ & $0.0485(2)$ & $-0.2810(4)$ & $43(1)$ \\
C5 & $0.3113(1)$ & $0.1455(2)$ & $-0.1359(5)$ & $45(1)$ \\
C6 & $0.2324(1)$ & $0.1356(2)$ & $-0.0868(5)$ & $45(1)$ \\
C7 & $0.1066(1)$ & $0.0187(2)$ & $-0.1110(5)$ & $46(1)$ \\
C8 & $0.4728(1)$ & $0.1508(2)$ & $-0.2335(7)$ & $58(1)$ \\
H1 & $0.016(2)$ & $0.089(3)$ & $0.084(8)$ & $135(11)^{\mathrm{a}}$ \\
H2 & $0.196(1)$ & $-0.137(2)$ & $-0.401(5)$ & $53(5)^{\mathrm{a}}$ \\
H3 & $0.329(1)$ & $-0.121(2)$ & $-0.476(5)$ & $61(6)^{\mathrm{a}}$ \\
H5 & $0.341(1)$ & $0.220(2)$ & $-0.066(5)$ & $56(6)^{\mathrm{a}}$ \\
H6 & $0.207(1)$ & $0.200(2)$ & $0.017(5)$ & $54(5)^{\mathrm{a}}$ \\
H81 & $0.451(1)$ & $0.228(3)$ & $-0.349(7)$ & $87(8)^{\mathrm{a}}$ \\
H82 & $0.526(1)$ & $0.129(2)$ & $-0.300(6)$ & $82(7)^{\mathrm{a}}$ \\
H83 & $0.475(1)$ & $0.164(2)$ & $0.028(6)$ & $77(7)^{\mathrm{a}}$ \\
\hline
\end{tabular}

${ }^{a}$ Isotropically refined. 


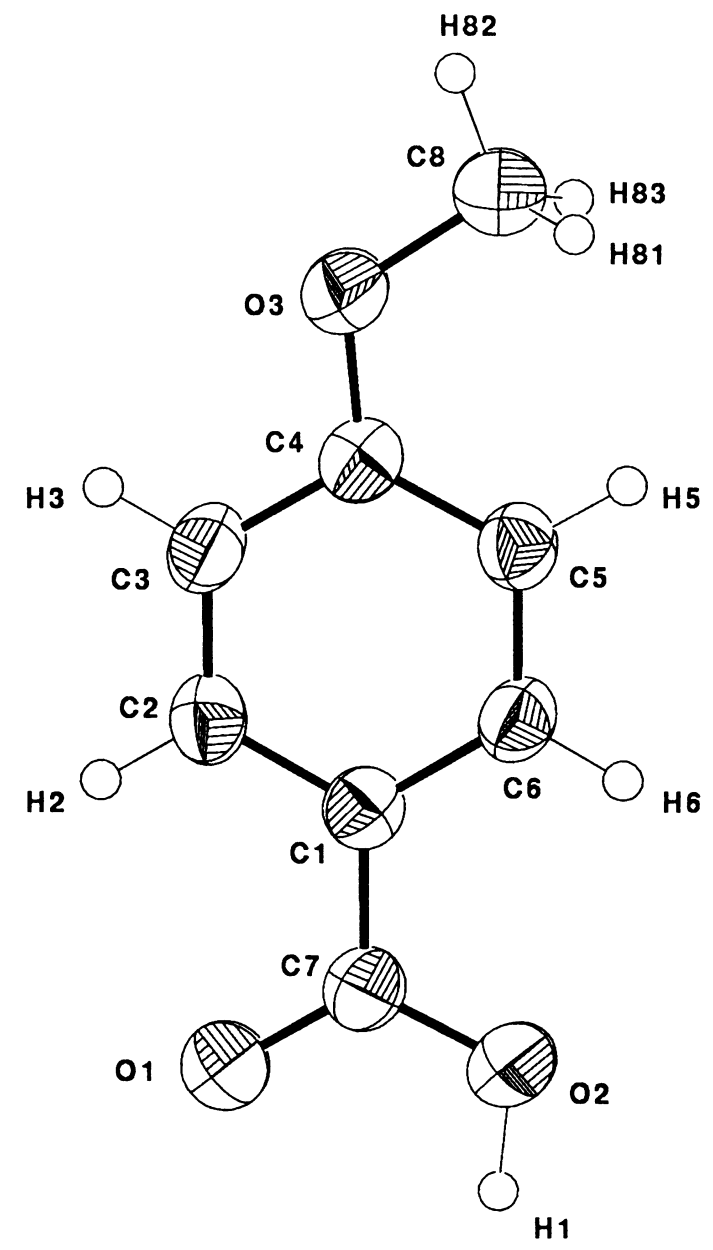

Fig. 1. ORTEPII plot of the anisic acid molecule, with the numbering of the atoms.

Fig. 1 is an ORTEPII [24] plot showing the numbering scheme adopted for the atoms and the corresponding thermal ellipsoids, while the packing is depicted in Fig. 2. Bond lengths and angles calculated from the X-ray data are presented in Table 2, where the corresponding ab initio values are also shown. In addition, Table 2 also gives the bond path angles resulting from the topological analysis of the theoretical charge density. The equation of the least-squares plane through the six carbon atoms of the ring and the displacement of all atoms from this plane, as determined from X-ray diffraction, are given in Table 3.

The X-ray data are in very good agreement with the results of the work of Colapietro and Domenicano [6], all bond distances and angles lying within 2 standard deviations. Thus, our concern that the procedure of discarding the weak reflections used by these authors might bias the structural results was not confirmed in this case. The precision on the structural parameters obtained in both works is also comparable, although it is systematically slightly better for our data: mean esd of $0.002 \AA$ for $\mathrm{C}-\mathrm{C}$ and $\mathrm{C}-\mathrm{O}$ bond lengths $(0.003 \AA$ in [6]), $0.02 \AA$ for $\mathrm{C}-\mathrm{H}$ bond lengths (0.04 in [6]), $0.2^{\circ}$ for angles not involving $\mathrm{H}$-atoms in both works, and $1-1.5^{\circ}$ for angles involving $\mathrm{H}$-atoms $\left(1.5-2^{\circ}\right.$ in [6]).

The main structural characteristics of crystalline anisic acid are as follows: (i) the benzene ring is planar within the experimental error; (ii) the carboxyl group is bent out of the benzenic plane, rather than twisted about the $\mathrm{C} 1-\mathrm{C} 7$ bond (the $\mathrm{O} 1, \mathrm{O} 2$ and $\mathrm{C} 7$ atoms were found to be bent in the same direction); (iii) the methoxy oxygen atom $\mathrm{O} 3$ is almost exactly in the plane of the benzenic ring; and (iv) the observed twist angles between the two planes $\mathrm{C} 8-\mathrm{O} 3-\mathrm{C} 4$ and $\mathrm{O} 1-\mathrm{C} 7-\mathrm{O} 2$ and the ring are $3.2(3)^{\circ}$ and $4.0(2)^{\circ}$, which compare well with the previously reported values of $3.3^{\circ}$ and $3.9^{\circ}[6]$.

The molecules of anisic acid are hydrogen-bonded in pairs across a centre of symmetry. The geometrical parameters for the $\mathrm{O} 2-\mathrm{H} 1 \cdots \mathrm{O}\left(1^{\prime}\right)$ hydrogen bond are: $\mathrm{O} 2-\mathrm{O}\left(1^{\prime}\right)=2.630(2), \mathrm{O} 2-\mathrm{H} 1=1.09(3)$, $\mathrm{H} 1 \cdots \mathrm{O}\left(1^{\prime}\right)=1.55(3) \AA$, angle $\mathrm{O} 2-\mathrm{H}(1) \cdots \mathrm{O}\left(1^{\prime}\right)=$ $172(3)^{\circ}$.

The high value of the displacement parameter $\left(U_{\text {iso }}=0.135 \AA^{2}\right)$ of the carboxylic $\mathrm{H}$ atom, a feature also found in the work of Colapietro and Domenicano, suggests that there might be some degree of rotational disorder in the carboxy group. This situation is not uncommon in other carboxylic acids $[25,26]$.

The 3-21G calculated values for the geometrical parameters (bond lengths and bond angles) of anisic acid compare favourably with typical ab initio values for di-substituted aromatic molecules [27,28] and for both the $-\mathrm{COOH}[29]$ and $-\mathrm{OCH}_{3}$ [30] moieties. For instance, the mean differences between the bond lengths and bond angles of the $-\mathrm{COOH}$ group in this molecule and in benzoic acid are less than $0.009 \AA$ and $0.8^{\circ}$, respectively. The $\mathrm{C} 1-\mathrm{C} 7$ bond length $(1.465 \AA)$ is very similar to that of the central bonds in both butadiene [31] and halogeno-substituted 1,3-dienes [32] (approx. 1.467-1.463 $\AA$ ), being significantly shorter than a typical $\mathrm{C}-\mathrm{C}$ single bond (approx. $1.54 \AA$ ) and considerably longer than the 
Table 2

Geometrical parameters for anisic acid determined by X-ray and 3-21G ab initio calculations

\begin{tabular}{|c|c|c|c|c|c|c|}
\hline \multicolumn{3}{|c|}{ Bond length/A } & \multicolumn{4}{|l|}{ Bond angle/ $/^{\circ}$} \\
\hline & \multirow[t]{2}{*}{ X-ray } & \multirow[t]{2}{*}{$\mathrm{Ab}$ initio } & & \multirow[t]{2}{*}{$\mathrm{X}$-ray } & \multicolumn{2}{|c|}{ Ab initio } \\
\hline & & & & & Geom. & B. Path \\
\hline $\mathrm{C} 1-\mathrm{C} 2$ & $1.393(2)$ & 1.391 & $\mathrm{C} 7-\mathrm{O} 2-\mathrm{H} 1$ & 112.(2) & 111.4 & 98.0 \\
\hline $\mathrm{C} 1-\mathrm{C} 6$ & $1.386(2)$ & 1.380 & $\mathrm{C} 4-\mathrm{O} 3-\mathrm{C} 8$ & $118.20(14)$ & 121.3 & 104.6 \\
\hline $\mathrm{C} 2-\mathrm{C} 3$ & $1.370(3)$ & 1.371 & $\mathrm{C} 2-\mathrm{C} 1-\mathrm{C} 6$ & $118.9(2)$ & 119.7 & 122.7 \\
\hline $\mathrm{C} 3-\mathrm{C} 4$ & $1.392(3)$ & 1.393 & $\mathrm{C} 2-\mathrm{C} 1-\mathrm{C} 7$ & $120.2(2)$ & 118.1 & 117.1 \\
\hline $\mathrm{C} 4-\mathrm{C} 5$ & $1.390(2)$ & 1.385 & $\mathrm{C} 6-\mathrm{C} 1-\mathrm{C} 7$ & $120.8(2)$ & 122.2 & 120.2 \\
\hline C5-C6 & $1.383(3)$ & 1.382 & $\mathrm{C} 1-\mathrm{C} 2-\mathrm{C} 3$ & $120.6(2)$ & 120.3 & 119.9 \\
\hline $\mathrm{C} 2-\mathrm{H} 2$ & $0.96(2)$ & 1.071 & $\mathrm{C} 1-\mathrm{C} 2-\mathrm{H} 2$ & $119.9(11)$ & 118.8 & 118.3 \\
\hline $\mathrm{C} 3-\mathrm{H} 3$ & $0.94(2)$ & 1.069 & $\mathrm{C} 3-\mathrm{C} 2-\mathrm{H} 2$ & $119.5(11)$ & 120.9 & 121.8 \\
\hline C5-H5 & $0.98(2)$ & 1.069 & $\mathrm{C} 2-\mathrm{C} 3-\mathrm{C} 4$ & $120.2(2)$ & 120.0 & 119.8 \\
\hline C6-H6 & $0.95(2)$ & 1.069 & $\mathrm{C} 2-\mathrm{C} 3-\mathrm{H} 3$ & $121.5(12)$ & 121.9 & 123.4 \\
\hline $\mathrm{C} 1-\mathrm{C} 7$ & $1.458(3)$ & 1.465 & $\mathrm{C} 4-\mathrm{C} 3-\mathrm{H} 3$ & $118.3(12)$ & 118.2 & 116.8 \\
\hline $\mathrm{C} 7-\mathrm{O} 1$ & $1.254(2)$ & 1.207 & $\mathrm{O} 3-\mathrm{C} 4-\mathrm{C} 3$ & $115.5(2)$ & 116.0 & 114.1 \\
\hline $\mathrm{C} 7-\mathrm{O} 2$ & $1.287(2)$ & 1.358 & $\mathrm{O} 3-\mathrm{C} 4-\mathrm{C} 5$ & $124.5(2)$ & 124.2 & 117.4 \\
\hline $\mathrm{O} 2-\mathrm{H} 1$ & $1.09(3)$ & 0.967 & $\mathrm{C} 3-\mathrm{C} 4-\mathrm{C} 5$ & $120.0(2)$ & 119.8 & 128.5 \\
\hline $\mathrm{C} 4-\mathrm{O} 3$ & $1.354(2)$ & 1.362 & $\mathrm{C} 4-\mathrm{C} 5-\mathrm{C} 6$ & $119.2(2)$ & 119.8 & 120.2 \\
\hline $\mathrm{O} 3-\mathrm{C} 8$ & $1.432(2)$ & 1.439 & $\mathrm{C} 4-\mathrm{C} 5-\mathrm{H} 5$ & $120.9(11)$ & 120.8 & 119.2 \\
\hline C8-H81 & $1.00(3)$ & 1.082 & C6-C5-H5 & $119.9(11)$ & 119.3 & 120.6 \\
\hline $\mathrm{C} 8-\mathrm{H} 82$ & $1.00(2)$ & 1.077 & $\mathrm{C} 1-\mathrm{C} 6-\mathrm{C} 5$ & $121.2(2)$ & 120.3 & 119.8 \\
\hline \multirow[t]{11}{*}{$\mathrm{C} 8-\mathrm{H} 83$} & $1.04(2)$ & 1.082 & C1-C6-H6 & $118.0(12)$ & 119.3 & 119.4 \\
\hline & & & C5-C6-H6 & $120.8(12)$ & 120.4 & 120.8 \\
\hline & & & $\mathrm{O} 1-\mathrm{C} 7-\mathrm{O} 2$ & $121.9(2)$ & 121.6 & 118.1 \\
\hline & & & $\mathrm{O} 1-\mathrm{C} 7-\mathrm{C} 1$ & $120.4(2)$ & 125.7 & 132.6 \\
\hline & & & $\mathrm{O} 2-\mathrm{C} 7-\mathrm{C} 1$ & $117.7(2)$ & 112.7 & 109.3 \\
\hline & & & $\mathrm{O} 3-\mathrm{C} 8-\mathrm{H} 81$ & $111.4(14)$ & 111.2 & 106.2 \\
\hline & & & $\mathrm{O} 3-\mathrm{C} 8-\mathrm{H} 82$ & $103.7(13)$ & 105.4 & 104.3 \\
\hline & & & $\mathrm{O} 3-\mathrm{C} 8-\mathrm{H} 83$ & $110.5(12)$ & 111.2 & 106.2 \\
\hline & & & $\mathrm{H} 81-\mathrm{C} 8-\mathrm{H} 82$ & 111.(2) & 109.7 & 113.6 \\
\hline & & & $\mathrm{H} 81-\mathrm{C} 8-\mathrm{H} 83$ & 107.(2) & 109.6 & 112.1 \\
\hline & & & $\mathrm{H} 82-\mathrm{C} 8-\mathrm{H} 83$ & 113.(2) & 109.7 & 113.6 \\
\hline
\end{tabular}

Numbers in parentheses are estimated standard deviations in the least significative digits.

conjugated $\mathrm{C}-\mathrm{C}$ bonds of the aromatic ring (approx. $1.39 \AA$ A). Thus, these results point to a limited extent of conjugation in this bond. On the other hand, both the $\mathrm{C} 4-\mathrm{O} 3$ and $\mathrm{O} 3-\mathrm{C} 8$ bond lengths in the studied molecule (1.362 and $1.438 \AA$, respectively) agree with typical values for these kinds of bonds [33].

The calculated skeletal bond lengths and angles show a remarkable agreement with the experimental $\mathrm{X}$-ray values (see Table 2). The largest differences occur in the bond lengths and bond angles of the carboxylic group (i.e. $\mathrm{C} 7-\mathrm{O} 1,2$ and $\mathrm{C} 1-\mathrm{C} 7-\mathrm{O} 1,2)$ and for the $\mathrm{C} 4-\mathrm{O} 3-\mathrm{C} 8$ bond angle.

These results can be easily understood taking into account both the intermolecular interactions present in the crystal and the $C_{\mathrm{s}}$ symmetry restriction imposed to the MO calculations. The hydrogen bonding within the crystal involves the carboxyl groups of adjacent molecules (the hydrogen bond distance $\mathrm{O} 2-\mathrm{H} 1-\mathrm{O}^{\prime} 1$ is 2.630(2) $\AA$ ) and tends to make the two $\mathrm{C}-\mathrm{O}$ carboxyl bonds more similar to each other, thus leading to longer $\mathrm{C} 7-\mathrm{O} 1$ and shorter $\mathrm{C} 7-\mathrm{O} 2$ distances in the crystal than in the isolated molecule (see Table 2). Indeed, this is the main reason why the corresponding geometrical parameters of the $\mathrm{C}=\mathrm{O}$ and $\mathrm{C}-\mathrm{OH}$ sides of the anisic acid molecule differ less in the crystal than in the ab initio calculated structure. In turn, the relatively large difference between the experimental and calculated $\mathrm{C} 4-\mathrm{O} 3-\mathrm{C} 8$ bond angles results mainly from the symmetry constraints imposed on the MO calculations during the geometry optimization, 


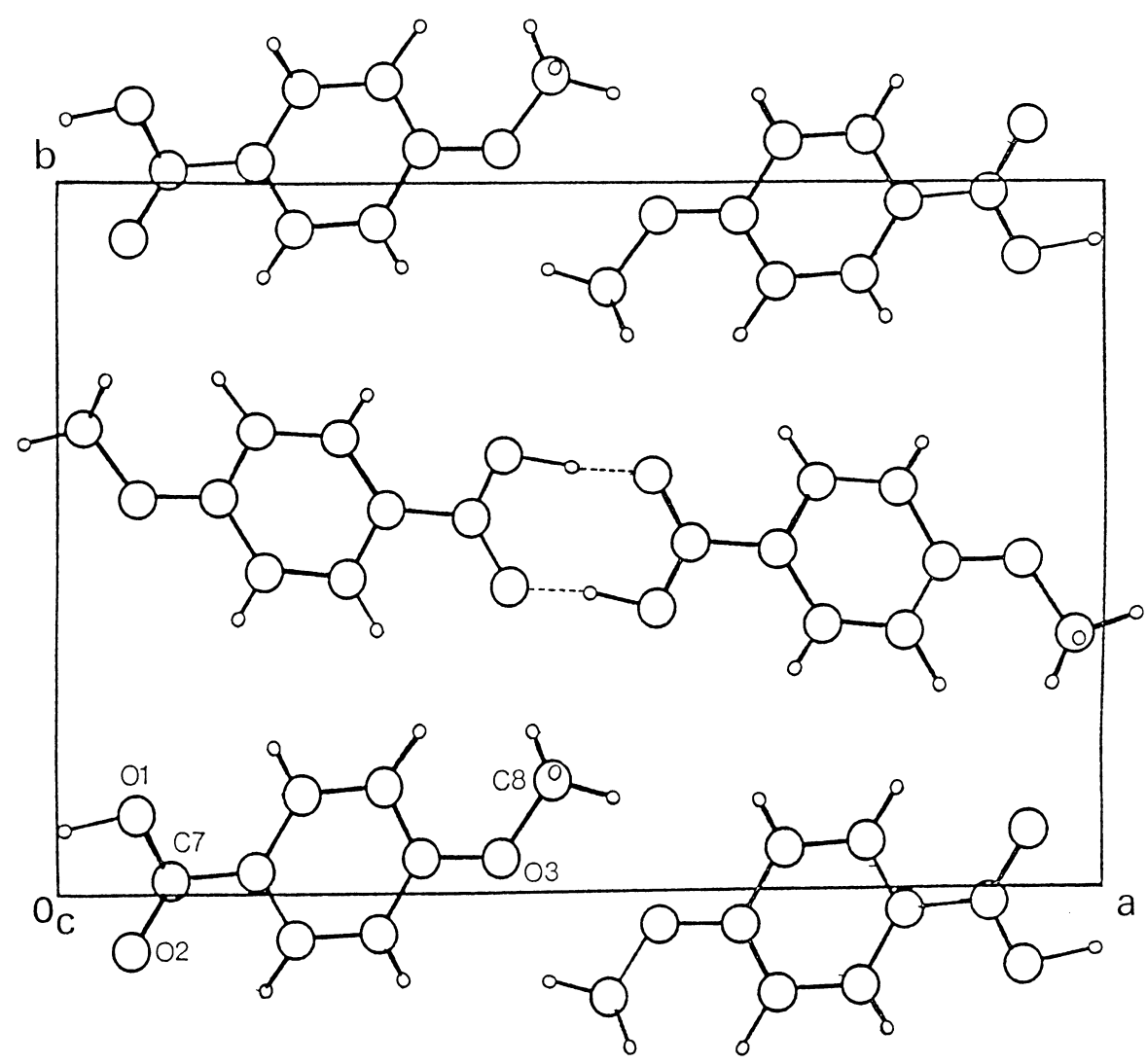

Fig. 2. View along the $c$-axis of the unit cell content.

which lead to an overestimation of the repulsive interactions between the methyl group and the aromatic ring.

The structural results are consistent with a considerably strong influence of the methoxy substituent on the electronic charge distribution within the aromatic ring. In addition, these results also reflect the presence of steric interactions between $\mathrm{H} 5$ and the two methyl hydrogen atoms, H81 and H83. In particular, the marked bending of the $\mathrm{C} 4-\mathrm{O} 3$ bond in the plane of the ring is probably determined by this last factor, as mentioned above.

The shortest $\mathrm{C}-\mathrm{C}$ bond length of the aromatic ring was determined to be $\mathrm{C} 2-\mathrm{C} 3$, while $\mathrm{C} 1-\mathrm{C} 2$ and $\mathrm{C} 3-$ $\mathrm{C} 4$ are the longest ones (see Table 2). Thus, $\mathrm{C} 2-\mathrm{C} 3$ is the strongest bond and $\mathrm{C} 1-\mathrm{C} 2$ and $\mathrm{C} 3-\mathrm{C} 4$ correspond to the weakest bonds. From a combined analysis of $\mathrm{X}$-ray charge density data and $\sigma / \pi$ partition of the calculated overlap populations associated with these bonds, it could be concluded, in consonance with the structural results, that the $\mathrm{C} 2-\mathrm{C} 3$ bond has a considerably large double bond character that and $\mathrm{C} 3-\mathrm{C} 4$ is a weak bond with respect to both the $\sigma$ and $\pi$ electronic systems. In addition, it could also be concluded that the weakness of $\mathrm{C} 1-\mathrm{C} 2$ arises mainly from its $\sigma$ component.

The calculated values of the charge density $(\rho)$ at the bond critical points in the molecular plane (a bond

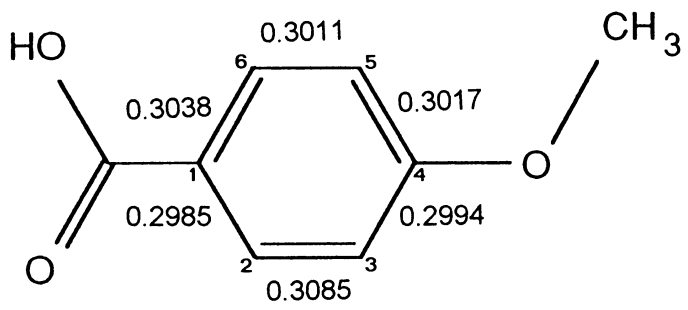

Fig. 3. Calculated values of the charge density (units of $e$ ) at the bond critical points. 
Table 3

Coefficients of the equation of the least-squares ring plane $(A x+B y+C z-D=0)^{\mathrm{a}}$ and displacements of the atoms from this plane $(\AA)$

\begin{tabular}{llrrr}
\hline Coefficient & Atom & Distance & Atom & Distance \\
\hline$A:-2.704(12)$ & C1 & $-0.004(1)$ & O3 & $-0.03(3)$ \\
$B:-4.244(8)$ & C2 & $0.002(1)$ & H1 & $-0.20(3)$ \\
$C: 3.476(2)$ & C3 & $0.001(1)$ & H2 & $0.04(2)$ \\
$D: 0.247(4)$ & C4 & $-0.003(1)$ & H3 & $0.00(2)$ \\
& C5 & $0.001(1)$ & H5 & $-0.01(2)$ \\
& C6 & $0.002(1)$ & H6 & $-0.02(2)$ \\
& C7 & $-0.070(2)$ & H81 & $-0.71(3)$ \\
& O1 & $-0.074(4)$ & H82 & $-0.93(2)$ \\
\end{tabular}

${ }^{\mathrm{a}}$ Fitted to the six carbon atoms.

critical point is defined as the point on the line of maximum charge density linking two nuclei where $\rho$ reaches its minimum value [12,13]), shown in Fig. 3, are also in agreement with these conclusions. The critical point associated with the $\mathrm{C} 2-\mathrm{C} 3$ bond is that corresponding to the highest electronic density, while those associated with the $\mathrm{C} 1-\mathrm{C} 2$ and $\mathrm{C} 2-\mathrm{C} 3$ bonds correspond to the lowest values of $\rho$.

The calculated Mulliken atomic charges on the aromatic ring carbon atoms (Table 4)

$q(\mathrm{C} 5) \approx q(\mathrm{C} 1)>q(\mathrm{C} 3)>q(\mathrm{C} 6) \approx q(\mathrm{C} 2) \gg q(\mathrm{C} 4)$

can also be used to study the electronic charge distribution within the ring. The results point to a more important contribution from canonical forms I and III, shown in Fig. 4, when compared with that of canonical form II.

The greater importance of I compared with II had already been suggested [6], on the basis of structural

Table 4

3-21G net atomic charges $(e)$ of anisic acid

\begin{tabular}{lrlr}
\hline Atom & Charge & Atom & Charge \\
\hline C1 & -0.285 & C7 & 0.953 \\
C2 & -0.164 & O1 & -0.629 \\
C3 & -0.265 & O2 & -0.734 \\
C4 & 0.441 & H1 & 0.416 \\
C5 & -0.290 & & \\
C6 & -0.172 & O3 & -0.737 \\
H2 & 0.288 & C8 & -0.275 \\
H3 & 0.269 & H81 & 0.204 \\
H5 & 0.251 & H82 & 0.239 \\
H6 & 0.288 & H83 & 0.204 \\
\hline
\end{tabular}

$e=1.6021892 \times 10^{-19} \mathrm{C}$.
$\mathrm{X}$-ray data analysis alone. The relative importance of form III is now stressed; it can be used to evaluate the extension of the mesomerism involving the methoxy group. In addition, the large positive charge of $\mathrm{C} 4$ $(+0.443 e)$ suggests that canonical forms such as IV (see Fig. 4) - with a positive charge on $\mathrm{C} 4-$ may also be of considerable importance, though the $\sigma$ inductive electron-withdrawing effect of the methoxy group is certainly the main factor contributing to the low electron density on this atom.

The effects on the electronic structure of the aromatic ring caused by mesomerism involving the carboxylic group are not so important as those due to the mesomerism involving the methoxy substituent. This is easy to understand, considering the presence of the competitive mesomerism within the carboxylic group:

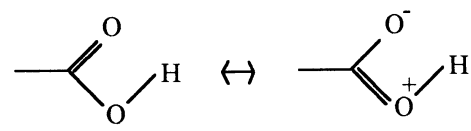

However, the results also point to a greater importance of canonical forms V and VI when compared with the canonical form VII (see Fig. 4).

Intramolecular interactions can also be studied from the comparison between geometric angles and the corresponding angles defined by the associated paths (the bond path is defined as the path of maximum electron density forming a pair of bonded nuclei $[12,13])$.

In the absence of a constraint external to the bonds forming a given angle, the bond paths are expected to be collinear with the lines drawn between the nuclei. However, if the bonds are distorted as a result of steric 
<smiles>C[O+]=C1C=CC(C)=CC1</smiles>

$\mathrm{COOH}$<smiles>C[O+]=C1C=CC(C)=CC1</smiles>

$\mathrm{COOH}$<smiles>C[O+]=C1C=CC(C)=CC1</smiles>

$\mathrm{COOH}$<smiles>COc1ccc(C)cc1</smiles>

$\mathrm{COOH}$
I
II

III

IV<smiles>CO[C+]1C=CC(=C([O-])O)C=C1</smiles>

$\mathrm{V}$<smiles>COC1=C[C]C(=C([O-])O)C=C1</smiles>

VI<smiles>COC1=C[CH+]C(=C([O-])O)C=C1</smiles>

VII

Fig. 4. Relevant canonical forms of anisic acid.

or coulombic interactions between substituents, or the formation of a ring, the bond paths will bend [34], resulting in a bond path angle $\left(\alpha_{\mathrm{bp}}\right)$ which differs from the geometrical bond angle $\left(\alpha_{\mathrm{g}}\right)$. A negative value of $\Delta \alpha=\alpha_{\mathrm{bp}}-\alpha_{\mathrm{g}}$ suggests a repulsive interaction between the two outer atoms of those forming the bond angle. A positive value can indicate an attractive interaction or reflect a smaller repulsion than those associated with the vicinal angles. Thus, the results presented in the Fig. 5 reveal: (i) the usual inward forces observed in benzenic rings, which correlate with its great stability;

(ii) the presence of the previously mentioned steric repulsive interaction between $\mathrm{H} 5$ and the methyl hydrogen atoms;

(iii) the existence of repulsive interactions induced by the lone electron pairs of the divalent oxygen atoms (O2 and $\mathrm{O} 3)$;

(iv) the presence of a weak attractive interaction between the carbonyl oxygen and $\mathrm{H} 2$. 


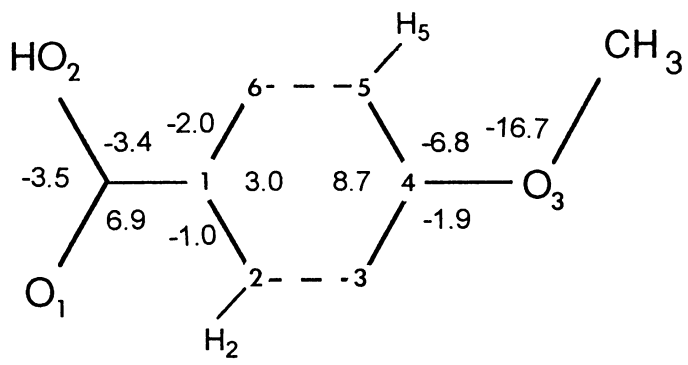

Fig. 5. Differences between bond path angles and geometrical angles $\left(\alpha_{\mathrm{bp}}-\alpha_{\mathrm{g}}\right)$ close to the carboxylic or methoxy substituents.

Another interesting analysis that can be made using the bond path angles relates its magnitude to the electronegativity of the atoms. It has been shown previously that, around a given atom, the angle opposite to the most electronegative bonded atom should have the largest bond path angle, while the bond orbital directed towards this atom should have the highest $p$ character [34]. This correlation between the electronegativity of the substituent and the associated opposite bond path angle is clearly seen around the carbonyl bond (Fig. 6), in agreement with previously obtained results for other carbonyl molecules [34]. In addition, if we look at the bond path angles around $\mathrm{C} 1$ and $\mathrm{C} 4$ (see Fig. 6), we can conclude that $\xi(\mathrm{C} 3)>\xi(\mathrm{C} 5)$ and $\xi(\mathrm{C} 7)>\xi(\mathrm{C} 2)>\xi(\mathrm{C} 6)$, where $\xi(\alpha)$ represents the electronegativity of the $\alpha$ carbon atom. Thus, these results are consistent with the calculated atomic charges $(q(\mathrm{C} 7)>q(\mathrm{C} 2)>q(\mathrm{C} 6)$; $q(\mathrm{C} 3)>q(\mathrm{C} 5))$. Indeed, one should note that these results could not be obtained using the conventional geometric angles: around the $\mathrm{C} 1$ carbon atom, for instance, the largest geometrical angle is $\mathrm{C} 6-\mathrm{C} 1-$ $\mathrm{C} 7$, whilst the largest bond path angle is $\mathrm{C} 2-\mathrm{C} 1-\mathrm{C} 6$ (see Table 1).

\subsection{The $\mathrm{O}-\mathrm{CH}_{3}$ internal rotation}

It was shown that methyl-ring interactions play a very important role in determining the structure and electronic distribution of anisic acid. Thus, the study of the internal rotation about $\mathrm{O} 3-\mathrm{C} 8$ assumes particular importance.

Table 5 and Table 6 report the calculated changes in bond lengths, bond angles and atomic charges associated with the change in conformation from the minimum energy form $\left(\mathrm{C} 4-\mathrm{O} 3-\mathrm{C} 8-\mathrm{H}=180^{\circ}\right)$ to the
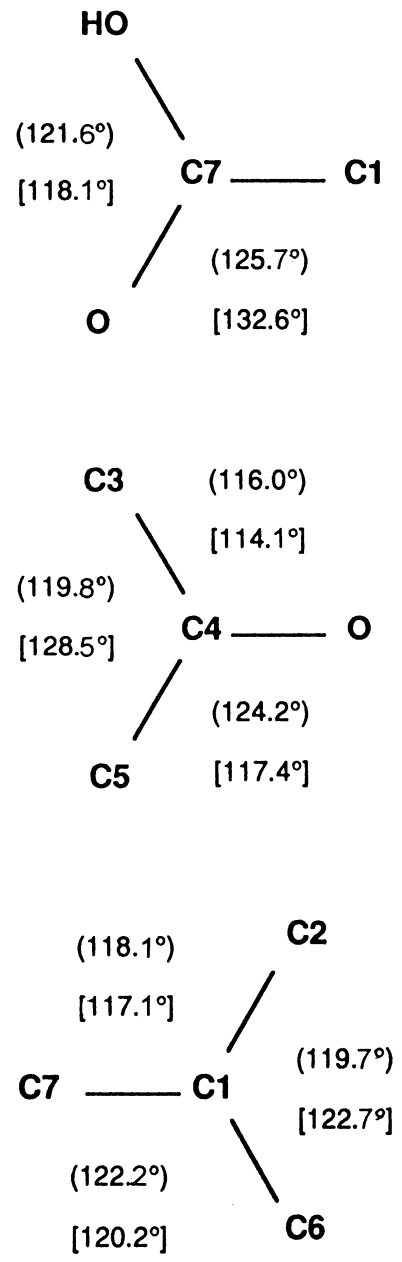

Fig. 6. Geometrical angles () and bond path angles [] around C7, C4 and $\mathrm{C} 1$.

internal rotation transition state $(\mathrm{C} 4-\mathrm{O} 3-\mathrm{C} 8-\mathrm{H}=$ $0^{\circ}$ ). As shown schematically in Fig. 7, these changes can be easily correlated with the increase in the energy of interaction (steric and electrostatic) between H5 and the methyl group, as the transition state structure has one of the methyl hydrogen atoms very close to $\mathrm{H} 5$. While the bond angles $\mathrm{H} 5-\mathrm{C} 5-\mathrm{C} 4-\mathrm{O} 3-\mathrm{C} 8-\mathrm{H} 82$ increase in order to increase the distance between $\mathrm{H} 5$ and H82, the coulombic repulsion between these two positive centres is reduced by a decrease in their net atomic charge. In particular, the flux of electrons within the methyl group is clearly shown in Fig. 7 (b).

The calculated energy barrier for $-\mathrm{CH}_{3}$ rotation amounts to approx. $12 \mathrm{~kJ} \mathrm{~mol}^{-1}$. This considerably high value of the energy barrier can also be correlated 
Table 5

Changes in bond lengths and bond angles with the $\mathrm{CH}_{3}$ internal rotation

\begin{tabular}{|c|c|c|c|c|}
\hline Bond & $\Delta$ bond length $/ \AA$ & Angle & $\Delta$ bond angle $/^{\circ}$ & $\Delta$ bond path angle $/^{\circ}$ \\
\hline $\mathrm{O} 3-\mathrm{C} 8$ & 0.002 & $\mathrm{O} 3-\mathrm{C} 4-\mathrm{C} 3$ & -0.9 & -1.1 \\
\hline $\mathrm{C} 8-\mathrm{H} 81$ & -0.003 & $\mathrm{O} 3-\mathrm{C} 4-\mathrm{C} 5$ & 1.2 & 1.0 \\
\hline \multirow[t]{8}{*}{$\mathrm{C} 8-\mathrm{H} 83$} & -0.003 & $\mathrm{C} 4-\mathrm{O} 3-\mathrm{C} 8$ & 3.9 & 3.2 \\
\hline & & $\mathrm{C} 4-\mathrm{C} 5-\mathrm{H} 5$ & 0.5 & 0.5 \\
\hline & & $\mathrm{O} 3-\mathrm{C} 8-\mathrm{H} 81$ & -3.4 & -0.8 \\
\hline & & $\mathrm{O} 3-\mathrm{C} 8-\mathrm{H} 82$ & 7.6 & 2.0 \\
\hline & & $\mathrm{O} 3-\mathrm{C} 8-\mathrm{H} 83$ & -3.4 & -0.8 \\
\hline & & $\mathrm{H} 81-\mathrm{C} 8-\mathrm{H} 82$ & -0.5 & -0.8 \\
\hline & & $\mathrm{H} 82-\mathrm{C} 8-\mathrm{H} 83$ & -0.5 & -0.8 \\
\hline & & $\mathrm{H} 81-\mathrm{C} 8-\mathrm{H} 83$ & 0.2 & 1.3 \\
\hline
\end{tabular}

$\Delta=($ transition state $)-($ minimum $)$

a)

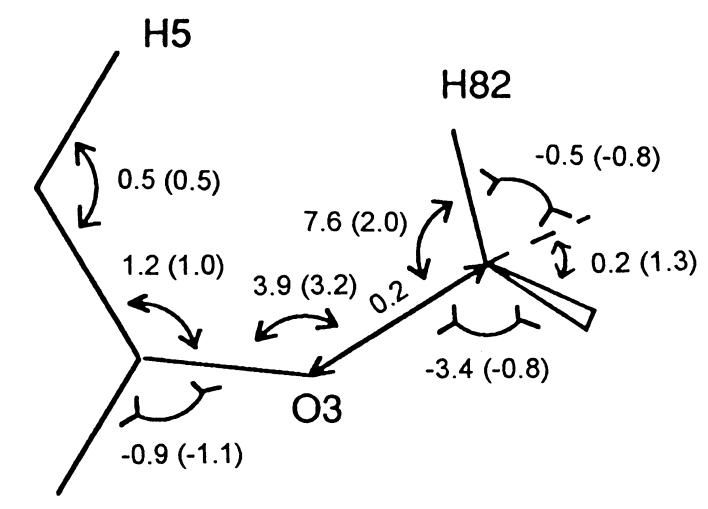

C3

b)

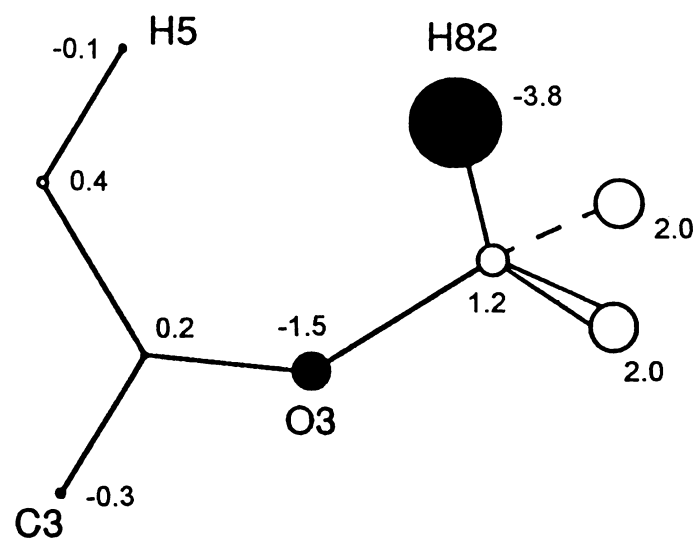

Fig. 7. Changes (a) in the geometry (units of $\AA \times 10^{-2}$, or degrees) and (b) in the atomic charges, associated with the methyl internal rotation. In (a), values in parentheses are changes in bond path angles. In (b), the radii of the circles are proportional to $\Delta q=\left(q_{\mathrm{TS}}-q_{\mathrm{min}}\right)$; black circles indicate increase and white circles decrease in negative charge. 


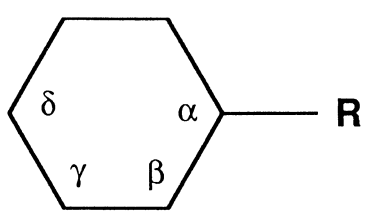

$$
\begin{gathered}
\Delta \xi=\xi-120 \\
\xi=\alpha, \beta, \gamma, \delta
\end{gathered}
$$

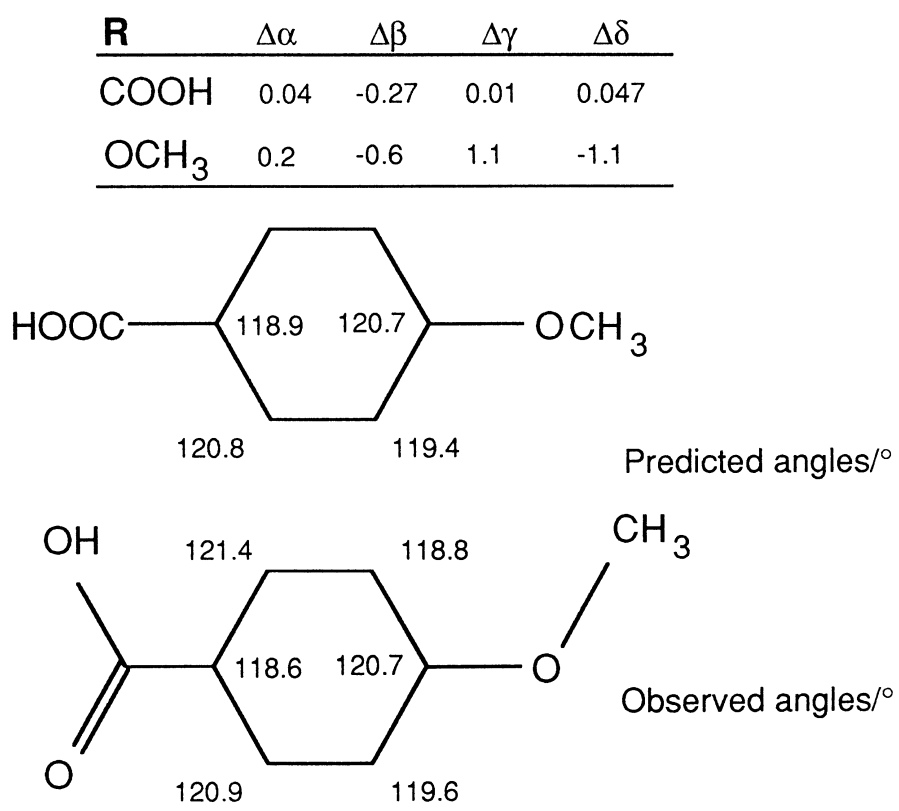

Fig. 8. Comparison of predicted and observed ring angles of anisic acid. Geometrical substituent parameters $\Delta \xi$ taken from [35,36].

with the presence of strong repulsive interactions involving the methyl group and $\mathrm{H} 5$ in the transition state. Thus, it can be concluded that the H5 $\cdots$ methyl repulsive interaction is important either from a

\section{Table 6}

Changes in the net atomic charges $(0.01 e)$ with the $\mathrm{CH}_{3}$ internal rotation

\begin{tabular}{lrlr}
\hline $\begin{array}{l}\text { Negatively } \\
\text { charged atoms }\end{array}$ & $\Delta q$ & $\begin{array}{l}\text { Positively } \\
\text { charged atoms }\end{array}$ & \multicolumn{1}{l}{$\Delta q$} \\
\hline O1 & -0.1 & C4 & 0.2 \\
O2 & 0.0 & C7 & -0.1 \\
O3 & -1.5 & H1 & 0.0 \\
C1 & -0.2 & H2 & -0.1 \\
C2 & 0.1 & H3 & -0.1 \\
C3 & -0.3 & H5 & -0.1 \\
C5 & 0.4 & H6 & 0.0 \\
C6 & 0.3 & H81 & 2.0 \\
C8 & 1.2 & H82 & -3.8 \\
& & H83 & 2.0 \\
\hline
\end{tabular}

$\Delta q=q($ transition state $)-q($ minimum $)$. structural or from an energetic point of view. Indeed, it is also noteworthy that, while the predicted ring angles, calculated using the geometrical substituent parameters taken from the literature $[35,36]$ reproduce quite well the observed ring angles of anisic acid (Fig. 8), the agreement is much better for the angles corresponding to the less strained side of the aromatic ring.

\section{Acknowledgements}

The authors are grateful for all computer assistance provided by the Centro de Informática da Universidade de Coimbra, and acknowledge the financial support from the Junta Nacional de Investigação Científica e Tecnológica (J.N.I.C.T.), Portugal, the PRAXIS XXI (2/2.1/QUI/412/94) and FEDER. R.F. also thanks Prof. R.F.W. Bader (Hamilton, Canada) for making available the PROAIM 
program package used in this study, and A M.-B. and J.A.P. thank Dr. M. Angela Domingues (LNETILisbon) for the facilities provided in using a CAD4 diffractometer where the X-ray data were collected.

\section{References}

[1] R.F. Bryan, J. Chem. Soc. (1960) 2517.

[2] R.F. Bryan, J. Chem. Soc. (1960) 1311.

[3] M. Parvez, Acta Cryst. C43 (1987) 2243.

[4] R.F. Bryan, L. Fallon, J. Chem. Soc. Perkin Trans. II (1975) 1175.

[5] R.F. Bryan, J.J. Jenkins, J. Chem. Soc. Perkin Trans. II (1975) 1171.

[6] M. Colapietro, A. Domenicano, Acta Cryst. B34 (1978) 3277.

[7] B. Jones, J. Chem. Soc. (1935) 1874.

[8] G.M. Bennet, B. Jones, J. Chem. Soc. (1939) 420.

[9] R.F. Bryan, J. Chem. Soc. B. (1967) 1311.

[10] F.L. Hirshfeld, D. Rabinovich, Acta Cryst. A29 (1973) 510.

[11] L. Arnberg, S. Hovmoller, S. Westman, Acta Cryst. A35 (1979) 497.

[12] R.F.W. Bader, S.G. Anderson, A.J. Duke, J. Am. Chem. Soc. 101 (1979) 1389.

[13] R.F.W. Bader, J. Chem. Phys. 73 (1980) 2871.

[14] F.W. Biegler-König, R.F.W. Bader, T.-H. Tang, J. Comput. Chem. 3 (1982) 317.

[15] G.M. Sheldrick, SHELXL93. Program for the Refinement of Crystal Structures. University of Göttingen, Germany, 1993.

[16] International Tables for Crystallography, Vol C, Table 4.2.6.8 and 6.1.1.4., Dordrecht, Kluwer Academic Publishers, 1992.

[17] M.J. Frisch, G.W. Trucks, H.B. Schlegel, P.M.W. Gill, B.G. Johnson, M.W. Wong, J.B. Foresman, M.A. Robb, M. Head-Gordon, E.S. Replogle, R. Gomperts, J.L. Andres, K. Raghavachari, J.S. Binkley, C. Gonzalez, R.L. Martin, D.J. Fox, D.J. Defrees, J. Baker, J.J.P. Stewart, J.A. Pople,
Program GAUSSIAN 92/DFT, Revision G.2, Gaussian Inc., Pittsburgh PA, USA, 1993.

[18] J.S. Binkley, J.A. Pople, W.J. Hehre, J. Am. Chem. Soc. 102 (1980) 939.

[19] R. Fausto, L.A.E. Batista de Carvalho, J.J.C. Teixeira-Dias, J. Mol. Struct. (Theochem.) 207 (1990) 67.

[20] L.A.E. Batista de Carvalho, J.J.C. Teixeira-Dias, R. Fausto, J. Mol. Struct. (Theochem.) 208 (1990) 109.

[21] J.J.C. Teixeira-Dias, L.A.E. Batista de Carvalho, R. Fausto, J. Comput. Chem. 12 (1991) 1047.

[22] P. Pulay, Mol. Phys. 17 (1969) 197.

[23] H.B. Schlegel, Ph.D. Thesis, Queens University Kingston, Kingston, Canada, 1975.

[24] C.K. Johnson, ORTEPII. Report ORNL-5138. Oak Ridge National Laboratory, Tennessee, USA, 1976.

[25] M. Colapietro, A. Domenicano, Acta Cryst. B38 (1982) 1953.

[26] M. Colapietro, A. Domenicano, G.P. Ceccarini, Acta Cryst. B35 (1979) 890.

[27] T. Burgi, S. Leutwuler, J. Chem. Phys. 101 (1994) 8418.

[28] T. Schaefer, R. Sebastian, Chem. Phys. Lett. 159 (1989) 212.

[29] C.W. Bock, M. Trachtman, P. George, J. Mol. Struct. (Theochem.) 122 (1985) 155.

[30] M.D.G. Faria, J.J.C. Teixeira-Dias, R. Fausto, Vibrat. Spectrosc. 2 (1991) 43.

[31] J.E. Rice, B. Liu, T. Lee, C.M. Rohlfing, Chem. Phys. Lett. 161 (1989) 277.

[32] C.M.C. Marques, J.J.C.T. Dias, P.J.A. Ribeiro-Claro, J. Raman Spectrosc. (submitted).

[33] M.R. Peterson, I.G. Csizmadia, J. Mol. Struct. (Theochem.) 123 (1985) 399.

[34] K.B. Wiberg, K.E. Laidig, J. Am. Chem. Soc. 109 (1987) 5935.

[35] A. Domenicano, G. Schultz, I. Hargittai, M. Colapietro, G. Portalone, P. George, C.W. Bock, Struct. Chem. 1 (1990) 107.

[36] A. Domenicano, P. Murrey-Rust, Tetrahedr. Lett. (1979) 2283. 